\title{
To asses the union time and pin track infection rate in ilizarov fixator using the Russian and rancho hybrid fixation technique
}

\author{
G. Siddalingamurthy ${ }^{1}$, Sheshagiri ${ }^{2, *}$, Anubhav Verma ${ }^{3}$ \\ ${ }^{\mathbf{1}}$ Associate Professor, ${ }^{\mathbf{2}}$ Assistant Professor, ${ }^{3}$ Resident, Dept. of Orthopaedics, JSS Medical College and Hospital Mysore, \\ Karnataka, India \\ *Corresponding Author: Sheshagiri \\ Email: drsheshu@yahoo.com
}

\begin{abstract}
Introduction: The treatment of complex proximal tibial fractures with ilizarov external fixators is slowly gaining more popularity and acceptability in traumatology, complex tibial plateau fractures pose a significant risk of soft tissue problems, edema and compartment syndrome, its management throws a great challenge. These fractures were treated with ilizarov external fixators.

Materials and Methods: The prospective study was conducted in JSS Medical College and Hospital over a period of April 2016 to September 2017. A total of 30 patients who were treated with ilizarov ring external fixator for schatzkers type V and VI tibial plateau fractures were included in the study, each patients were randomly assigned to be treated with two methods, the Russian technique and the Rancho hybrid fixation technique, these patients were followed up and their data with regard to fracture union time and pin tract infections were collected in a Microsoft excel and the results were scrutinised.

Results: There was a predominantly male population and the road traffic accidents was the most common followed by self-fall, The mean union time was $18.27+\_1.79$ weeks in the Russian technique and $23.47+\_2.72$ weeks in the rancho hybrid system the union time was assessed using the RUST criteria and The Rancho technique pin tract infection rate was $20 \%$ and it was $26.67 \%$ in the Russian technique, the incidence of pin tract infection was even though a little higher in the Russian technique the difference was not statistically significant (OR1.45(0.26-8.1)p0.5) the pin track infection was graded using the checkers and buns.

Conclusion: the ilizarov Russian technique fares over the rancho hybrid fixation technique in achieving union earlier by enhancing the micromotion at the fracture site being a less rigid construct.
\end{abstract}

Keywords: Ilizarov fixator, Russian technique, Rancho technique, Schatzkers type V and VI fractures, Union time, Pin tract infections.

\section{Introduction}

The aim of treatment of proximal tibial fractures schatzkers type $\mathrm{V}$ and VI high energy injures is to restore the articular congruity and re-establish the mechanical and anatomical axis leasing to a properly aligned knee. In view of the soft tissue injury associated with these fractures minimally invasive and stable ilizarov external fixator is becoming the choice of surgery. ${ }^{1}$

The articular incongruity acceptable in the proximal tibial plateau fractures is controversial, poorly treated fractures leads to articular incongruity and missed internal de arrangement of knee involving the ligaments and the menisci if not addressed leads to late post traumatic osteoarthritis. $^{2}$

The union time required for union of proximal tibial plateau fractures range from 12 to 24 weeks depending on the degree of comminution, closed or open injuries, and soft tissue coverage

The classical ilizarov technique ${ }^{3}$ developed and popularised by ilizarov of kurgan based on his original recommendations ${ }^{4}$ used 1.8 ilizarov wires and olive wires which was used to connect the rings to the bone, these wires are inserted to the bone following the rules of safe zones ${ }^{5}$ for trans osseous wire fixation ${ }^{6}$ and later tensioned using hand tensioning or the dynamometer and tensioned to about $90-130 \mathrm{~kg}$.

The rancho technique ${ }^{7}$ popularised by the Italians who modified the classical ilizarov technique by using a Schanz pin and wired combined (Hybrid system) to connect the rings to the bone following the same rules of safe zone for trans osseous wire / pin fixation to avoid injuring the vessels in the deeper planes, making the procedure easy and less time consuming.

The aim of the article is to assess the union time and pin tract infection rate of the two systems of ilizarov external fixators the one classical ilizarov technique described by ilizarov ${ }^{3}$ himself and the rancho system hybrid construct popularised by the Italians. ${ }^{7}$

\section{Materials and Methods}

The study was done in the department of orthopaedics JSS medical college and hospital over a period of April 2016 to September 2017, those who underwent ilizarov external fixator for the proximal tibial fractures type V and type VI, was included in the study, all the other patients who underwent monoaxial external fixator, open fractures, fractures associated soft tissue injuries requiring skin or muscle flaps were excluded from the study, these patients were operated by 2 sets of surgeons who exclusively followed the classical Russian and rancho hybrid ilizarov system respectively and the patients were randomly assigned to undergo surgery using both techniques.

All patients underwent surgery under general or spinal anaesthesia and the surgeons applied the ilizarov frame preassembled or locally assembled on the table, The post-operative protocol was to clean the pin tract sites of the ilizarov wires or the Schanz pin s with 
hydrogen peroxide twice daily, These patients were taught about the care of pin tract and dressings as followed in kurgan protocol. ${ }^{8}$ Most of the patients were made ambulant the very next day or a 3 days later depending on their pain tolerability and were taught range of motion exercises by the hospital physiotherapist during their stay in the hospital. The patients were called post operatively at two weeks, 6 weeks and every 6 weeks to assess pin tract infections and progression of union.
The data collected were documented and graded respectively for union of the fracture using the RUST criteria for assessing union ${ }^{9}$ and checkers and otter buns criteria for grading the pin tract infections. ${ }^{10}$ (Table 1)

All fixators were removed, once the union was achieved the frame was removed and knee brace was given and made to ambulate the next day, the progress of union and pin tract infection was assessed using the respective criteria every $6 w k s$ till the union was achieved.



Fig. 1
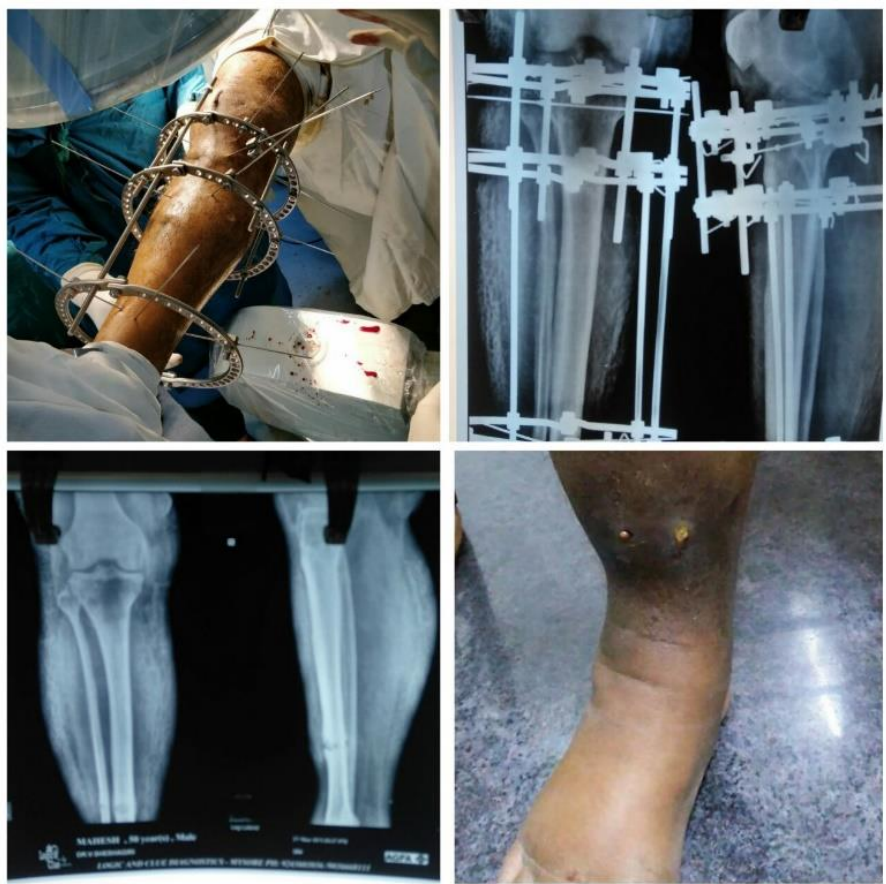

Fig. 2

\section{Results}

Results were analysed using the epi info statistical software version 7.2.2.6, the mean union observed in our study was $28.87+_{-} 3.48$ weeks, and in The Russian technique the mean union time was $18.27+\ldots 1.79$ weeks and that of the rancho technique the mean union time was

23.47+_2.72 weeks the difference of mean observed was statistically significant with $\mathrm{p}$ value of 0.0000 .

The union time among the female patients were $20.75+\_3.59$ and in males were $20.88+\_3.53$, p value 0.94 hence had no significance. 
Radiographic Criteria

\begin{tabular}{lcc} 
Score per Cortex $^{\text {a }}$ & Callus & Fracture L \\
\cline { 2 - 3 } & Absent & Visible \\
2 & Present & Visible \\
3 & Present & Invisible
\end{tabular}

a The individual cortical scores (anterior, posterior, medial, and lateral) are added to provide an overall RUST value ranging from 4 (ie, definitely not healed) to 12 (ie, definitely healed) for a set of radiographs.

Adapted with permission from Kooistra BW, Dijkman BG, Busse JW, Sprague S, Schemitsch $\mathrm{EH}$, Bhandari M: The radiographic union scale in tibial fractures: Reliability and validity. $J$ Orthop Trauma 2010;24(suppl 1):S81-S86.

Fig. 3: Rust Scoring

The Rancho technique pin tract infection rate was $20 \%$ and it was $26.67 \%$ in the Russian technique, the incidence of pin tract infection was even though a little higher in the Russian technique the difference was not statistically significant (OR1. 45(0.26-8.1)p0.5).

Table 1: Checkers and otter buns criteria

\begin{tabular}{|c|c|c|}
\hline Grade & Characteristics & Treatment \\
\hline & Minor infections & \\
\hline 1 & Slight redness, little discharge & Improved pin site care \\
\hline 2 & $\begin{array}{c}\text { Redness of skin, discharge, pain and tenderness in soft } \\
\text { tissue }\end{array}$ & Improved pin site care, oral antibiotics \\
\hline 3 & Grade 2 but no improvement with oral antibiotics & $\begin{array}{l}\text { Affected pin or pins resisted and external } \\
\text { fixation can be continued }\end{array}$ \\
\hline & Major infections & \\
\hline 4 & $\begin{array}{l}\text { Severe soft tissue infection involving several pins, } \\
\text { sometimes with associated loosening of the pin }\end{array}$ & External fixation must be abandoned \\
\hline 5 & Grade 4 but radiographic changes & External fixation must be abandoned \\
\hline 6 & $\begin{array}{l}\text { Infection after fixator removal, pin tract heals initially, } \\
\text { but will subsequently break down and discharge in } \\
\text { intervals, radiograph show new bone formation and } \\
\text { sometimes sequestrum }\end{array}$ & \\
\hline
\end{tabular}

\section{Discussion}

The proximal tibial plateau fractures are high energy injuries with high risk of soft tissue complications hence the use of plates and screws in a soft tissue compromised state is jeopardising, ${ }^{11}$ the versatile ilizarov external fixator comes to salvage in these cases with minimal damage to the soft tissue and providing three dimensional stability.

The classical ilizarov technique followed in kurgan Russia used ilizarov wires connecting the ring to the bone was based on the principles of enhancing micromotion at the fracture site encouraging bone union and making the whole construct less stiff. ${ }^{4}$

The rancho system of ilizarov basically a modification, a hybrid system where the Schanz and wires are used to connect the ring to the bone even though makes the procedure very simple and less chances of neurovascular injuries discourages the micromotion at the fracture site which is detrimental to bone union making the construct very stiff the union rate observed in our series being mean of $18.27+\_1.79$ weeks was less in Russian technique compared to the rancho at $23.47+22.72$ weeks which was statistically significant.

The complications like pin track infections constitute collectively to about $27 \%,{ }^{12}$ which is similar to our study, the exact incidence is unknown, and it's getting worse day by day in spite of the advances in sterilisation and surgical technique and post-operative care employed in clinical practice, it also depends on the fixator time with short frame time had $19 \%$ infections and the upper limb fractures had $14 \%$ infection rate, half the prevalence than in the lower limb fractures $31 \%$ infections ${ }^{12}$ probably because of the high vascularity in the upper limb.

Meticulous care of pin tract carries the benefit of longer fixator or frame time and better results. ${ }^{13}$ 


\section{Conclusion}

Both the system of ilizarov with its own merits and de merits, with the aim to achieve better and early union the classical ilizarov technique ${ }^{14}$ fares over the rancho system in achieving union by enhancing micromotion at the fractures site being a less rigid construct.

\section{References}

1. Reddy R S, Kumar C Y, Shah HM, Golla DK, Ganesh D J N, Kumar P A. Evaluation of Tibial Condyle Fractures Treated with Ilizarov Fixation, A Prospective Study. $J$ Clin Diagn Res JCDR. 2014;8(11):LC05-7.

2. Rüedi TP, Sommer C, Leutenegger A. New techniques in indirect reduction of long bone fractures. Clin Orthop. 1998;(347):27-34.

3. Gubin AV, Borzunov DY, Malkova TA. The Ilizarov paradigm: thirty years with the Ilizarov method, current concerns and future research. Int Orthop. 2013;37(8):1533-9.

4. Transosseous Osteosynthesis - Theoretical and Clinical Aspects of the Regeneration and Growth of Tissue | Gavriil A. Ilizarov | Springer [Internet]. [cited 2018 Apr 24]. Available from: https://www.springer.com/us/book/9783642843907

5. Nayagam S. Safe corridors in external fixation: the lower leg (tibia, fibula, hindfoot and forefoot). Strateg Trauma Limb Reconstr. 2007;2(2):105-10.

6. Smith-Nephew-Pin-atlas.pdf [Internet]. [cited 2018 Apr 25]. Available from: http://osteosyntese.dk/3033/SmithNephew-Pin-atlas.pdf

7. Green SA. The Ilizarov method: Rancho technique. Orthop Clin North Am. 1991;22(4):677-88.

8. Davies R, Holt N, Nayagam S. The care of pin sites with external fixation. J Bone Joint Surg Br. 2005;87(5):7169.

9. Leow JM, Clement ND, Tawonsawatruk T, Simpson CJ, Simpson AHRW. The radiographic union scale in tibial
(RUST) fractures: Reliability of the outcome measure at an independent centre. Bone Jt Res. 2016;5(4):116-21.

10. Kazmers NH, Fragomen AT, Rozbruch SR. Prevention of pin site infection in external fixation: a review of the literature. Strateg Trauma Limb Reconstr. 2016;11:7585.

11. Metcalfe D, Hickson CJ, McKee L, Griffin XL. External versus internal fixation for bicondylar tibial plateau fractures: systematic review and meta-analysis. J Orthop Traumatol off J Ital Soc Orthop Traumatol. 2015;16(4):275-85.

12. Iobst. A systematic review of incidence of pin track infections associated with external fixation [Internet]. 2016;2(1):6. Available from: http://www.jlimblengthrecon.org/article.asp?issn=24553719

13. Ferreira N, Marais LC. Prevention and management of external fixator pin track sepsis. Strateg Trauma Limb Reconstr. 2012;7(2):67-72.

14. Boutefnouchet T, Lakdawala AS, Makrides P. Outcomes following the treatment of bicondylar tibial plateau fractures with fine wire circular frame external fixation compared to open reduction and internal fixation: A systematic review. J Orthop. 2016;13(3):193-9.

How to cite this article: Siddalingamurthy G, Sheshagiri, Verma A. To asses the union time and pin track infection rate in ilizarov fixator using the Russian and rancho hybrid fixation technique. Indian J Orthop Surg. 2018;4(3):282-285. 